\title{
Bacterial Cellulose: Long-Term Biocompatibility Studies
}

\section{Renata A. N. Pértile ${ }^{\mathrm{a}}$, Susana Moreira ${ }^{\mathrm{a}}$, Rui M. Gil da Costa ${ }^{\mathrm{b}}$, Alexandra Correia ${ }^{\mathrm{c}}$} Luisa Guardão ${ }^{\mathrm{b}}$, Fátima Gartner ${ }^{\mathrm{b}, \mathrm{d}}$, Manuel Vilanova ${ }^{\mathrm{b}}$ and Miguel Gama ${ }^{\mathrm{a}, *}$

a IBB, Institute for Biotechnology and Bioengineering, Universidade do Minho, Campus de Gualtar, 4710-057 Braga, Portugal

${ }^{\mathrm{b}}$ ICBAS, Instituto de Ciências Biomédicas Abel Salazar (ICBAS), University of Porto, Largo Prof. Abel Salazar 2, 4099-003 Porto, Portugal

${ }^{c}$ CMBA, Centro de Biologia Molecular e Ambiental, da Universidade do Minho, Departamento de Biologia, Campus de Gualtar, 4710-057 Braga, Portugal

${ }^{\mathrm{d}}$ IPATIMUP, Institute of Molecular Pathology and Immunology, University of Porto, R. Dr. Roberto Frias, 4200-465 Porto, Portugal

Received 14 October 2010; accepted 29 May 2011

\section{Abstract}

The bacterial cellulose (BC) secreted by Gluconacetobacter xylinus is a network of pure cellulose nanofibres which has high crystallinity, wettability and mechanical strength. These characteristics make BC an excellent material for tissue engineering constructs, noteworthy for artificial vascular grafts. In this work, the in vivo biocompatibility of BC membranes produced by two G. xylinus strains was analyzed through histological analysis of long-term subcutaneous implants in the mice. The BC implants caused a mild and benign inflammatory reaction that decreased along time and did not elicit a foreign body reaction. A tendency to calcify over time, which may be related to the porosity of the BC implants, was observed, especially among the less porous BC-1 implants. In addition, the potential toxicity of BC nanofibres - obtained by chemicalmechanical treatment of BC membranes - subcutaneously implanted in mice was analysed through bone marrow flow cytometry, blood and histological analyses. At 2 and 4 months post-implantation, the nanofibres implants were found to accumulate intracellularly, in subcutaneous foamy macrophages aggregates. Moreover, no differences were observed between the controls and implanted animals in thymocyte populations and in B lymphocyte precursors and myeloid cells in the bone marrow.

(C) Koninklijke Brill NV, Leiden, 2011

Keywords

Bacterial cellulose, in vivo biocompatibility, nanofibres, tissue engineering 35

\footnotetext{
* To whom correspondence should be addressed. Tel.: (351-253) 604-400; Fax: (351-253) 678-986; e-mail: fmgama@deb.uminho.pt
} 


\section{Introduction}

Natural and synthetic polymers are used in the field of biomedical materials and tissue engineering in a variety of applications, including among others drug delivery, novel vascular grafts or scaffolds for in vitro and in vivo tissue engineering [1]. These polymers are available in a variety of configurations, including fibres, porous sponges and tubular structures [2]. Tissue engineering approaches typically employ scaffolds made of three-dimensional mimetics of the extracellular matrix (ECMs) to engineer new natural tissues from isolated cells. The scaffolds can be design as macroporous synthetic ECMs, which can regulate the organization of cells seeded into the matrix and its subsequent proliferation to form new tissues. Also, polymeric nanofibre matrices are one of the most promising tissue engineering biomaterials because their physical structure is similar to the fibrous proteins in native ECM. However, nanomaterials have unusual properties not found in the bulk material, and this is an important issue because nano-scale and high aspect ratio gives rise to different biological effects compared to micro- and macro-materials [3-6].

Cellulose is a naturally occurring linear homo-polymer of glucose, the most widespread polymer in nature [7]. Cellulose-based materials, such as oxidized cellulose and regenerated cellulose hydrogels, are mainly used in wound healing, as hemostatic agents, hemodialysis membranes and drug-releasing scaffolds $[1,8,9]$. Furthermore, several studies reported the applicability of cellulose for culturing cells (hepatocyte, chondrocyte, stem cells) and implantation (bone and cartilage development) [7, 10-13].

The bacterial cellulose (BC) secreted by Gluconacetobacter xylinus is chemically identical to plant cellulose but has different macromolecular properties and structure [14-17]. The cellulose secreted by these bacteria is a pure nanofibre network, which has high crystalinity, wettability, mechanical strength, in situ moldability and permeability for liquids and gases. Furthermore, it is simple to produce [18, 19]. These characteristics make $B C$ an excellent material for tissue engineering constructs. Indeed, its potential application as skin substitute for temporary covering of wounds and ulcers, dental implants, scaffold for tissue engineering of cartilage, nerves and blood vessels has been investigated [14, 15, 20, 21]. Furthermore, BC nanofibres seem to be a good material for biomedical applications since its toxicity has already been evaluated in our previous work, using in vitro assays [6], showing good biocompatibility and no evidence of genotoxicity.

In spite of cellulose-based materials being generally considered biocompatible, showing only a negligible foreign body and inflammatory response in vivo [10], several parameters must be evaluated as to assess the biocompatibility of an implanted material. Among them, the type and degree of inflammatory and immune response, disintegration, resistance and longevity of the implants in the host tissue have to be taken in consideration [22,23]. In this work, the biocompatibility of two different types of $\mathrm{BC}$ grafts was analyzed in a long-term approach. Moreover, the biocompatibility of $\mathrm{BC}$ nanofibres subcutaneously implanted in mice was also evaluated, including possible effects in lymphopoiesis. 


\section{Materials and Methods}

\subsection{Production of Bacterial Cellulose}

The pellicles of BC were produced by Gluconacetobacter xylinus ATCC 53582 (BC-1) and ATCC 10245 (BC-2) strains, cultured in Hestrin-Schramm medium [24], in 96-well polystyrene plates $(250 \mu \mathrm{l} / \mathrm{well})$, for 4 and 7 days, respectively, at $30^{\circ} \mathrm{C}$ in static culture. The membranes were purified using $2 \%$ sodium dodecyl sulfate (SDS) overnight, washed with distilled water until the complete removal of SDS and immersed in a $4 \% \mathrm{NaOH}$ solution, shaking for $90 \mathrm{~min}$ at $60^{\circ} \mathrm{C}$. After being neutralized, the pellicles were autoclaved in phosphate-buffered saline (PBS) and stored at $4{ }^{\circ} \mathrm{C}$. The $\mathrm{BC}$ nanofibres were produced according to Moreira et al. [6].

\subsection{Scanning Electron Microscopy}

The BC samples were sputter-coated with gold and examined by scanning electron microscopy (SEM). The analyses were performed on a scanning electron microscope (Leica S 360). CryoSEM was performed using a microscopy Model Gatan Alto 2500. Samples were fronzen in liquid nitrogen, cut to expose the BC-cells interface, and observed at $-150^{\circ} \mathrm{C}$.

\subsection{Animals}

The in vivo biocompatibility studies were performed using male BALB/c mice ( 8 weeks old) purchased from Charles River. The animals were kept at the Abel Salazar Institute for Biomedical Sciences of the University of Porto (ICBAS-UP) animal facilities during the experiments. All procedures involving the mice were performed according to the European Convention for the Protection of Vertebrate Animals used for Experimental and Scientific Purposes (ETS 123) and 86/609/EEC Directive and Portuguese Rules (DL 129/92).

\subsection{Subcutaneous Implantation}

The BC implants were surgically implanted subcutaneously, without fixation, in the back of the mice with each mouse receiving two implants (BC-1 $n=48$; BC-2 $n=80$ ). The mice were anesthetized by an intramuscular injection of a ketamine (Imalgene 1000, Material) and xylazine (Rompun 2\%, Bayer Healthcare) mixture, at a 50 and $10 \mathrm{mg} / \mathrm{kg}$ dose, respectively. The hair was removed and two small incisions were made in the skin as bilateral subcutaneous pockets along the backbone where the BC discs were implanted. Finally, the incision pockets were closed with stitches. The control animals received no implants. At least two animals were used for each post-implantation period analyzed (1 week, 1, 3, 5, 7 and 12 months). The aspect of the wound and the presence of oedema were evaluated before removing the implants. The implants were removed with the surrounding tissue to prevent damage to the tissue-implant interface, and immersed in formaldehyde for later histological evaluation.

The BC nanofibres were injected subcutaneously in 18 animals, divided into two groups ( 2 and 4 months post-implantation). Each animal received a $300-\mu l$ injection 
of nanofibre solution $(1 \mathrm{mg} / \mathrm{ml})$ on each side of the back, and for the control $300 \mu \mathrm{l}$ of physiological saline was used. After 2 and 4 months post-implantation, the animals were killed. Blood was sampled by cardiac puncture for blood analysis. Skin surrounding the injection sites and internal organs (liver, spleen, small intestine and mesenteric lymph nodes) were collected for histological analysis.

\subsection{Flow Cytometry}

For flow cytometry analyses, bone marrow cells from femurs and the thymus were collected, washed and ressuspended in PBS, supplemented with 1\% BSA and $10 \mathrm{mM}$ sodium azide. Flow cytometric analysis was performed in a FACScan with the CellQuest software (BD Biosciences), using the following antibodies: FITCconjugated rat anti-mouse IgM (Pharmingen), FITC-conjugated rat anti-mouse Ly6E and Ly-6C (Pharmingen), FITC-conjugated rat anti-mouse CD4 (Pharmingen), PE-conjugated rat anti-mouse CD8a (Pharmingen), PE-conjugated anti-mouse CD45R/B220 (Pharmingen), PE-conjugated anti-mouse CD11b (eBioscience). Dead cells were gated out through propidium iodide incorporation.

\subsection{Histological Analysis}

All samples were fixed in $10 \%$ neutral buffered formalin for $24 \mathrm{~h}$ and paraffin embedded. 4- $\mu \mathrm{m}$ thick sections were used for hematoxylin and eosin (H\&E) staining. Slides were examined under a light microscope (Nikon E600); measurements and photographs were obtained with a digital camera (Nikon DS-5M).

\section{Results}

\subsection{BC Morphology}

The SEM images of the $\mathrm{BC}$ membranes produced by the two strains used in this work (Fig. 1) exhibit structural differences. BC-1 has a more compact network while BC-2 has a highly porous structure. In addition, the BC-1 membranes obtained in the static culture present, as previously described [8], a more compact surface on the BC-air interface. The BC structure seemed to influence cell invasion and the implant's behaviour along time. The Cryosem results shows the compact a porous side of BC-1 membranes, and as can be seen in Fig. 1e and 1f, the compact side presents aggregated fibrillar structure, while in the porous side, fibres are more dispersed, and the structure have a higher porosity.

\subsection{BC Long-Term Biocompatibility}

On gross examination, the $\mathrm{BC}$ implants maintained their shape, but internal fissures lined with migrating mesenchymal cells were evident histologically. No clinical signs of inflammation were present at the incision sites. Cell in-growth was consistently more extensive on the BC-1 porous side (Fig. 2), where cells presented a spindle-shaped form. Integration with the host tissue was occasionally observed over time, with both materials evaluated; the tissue-implant interface being multi- 

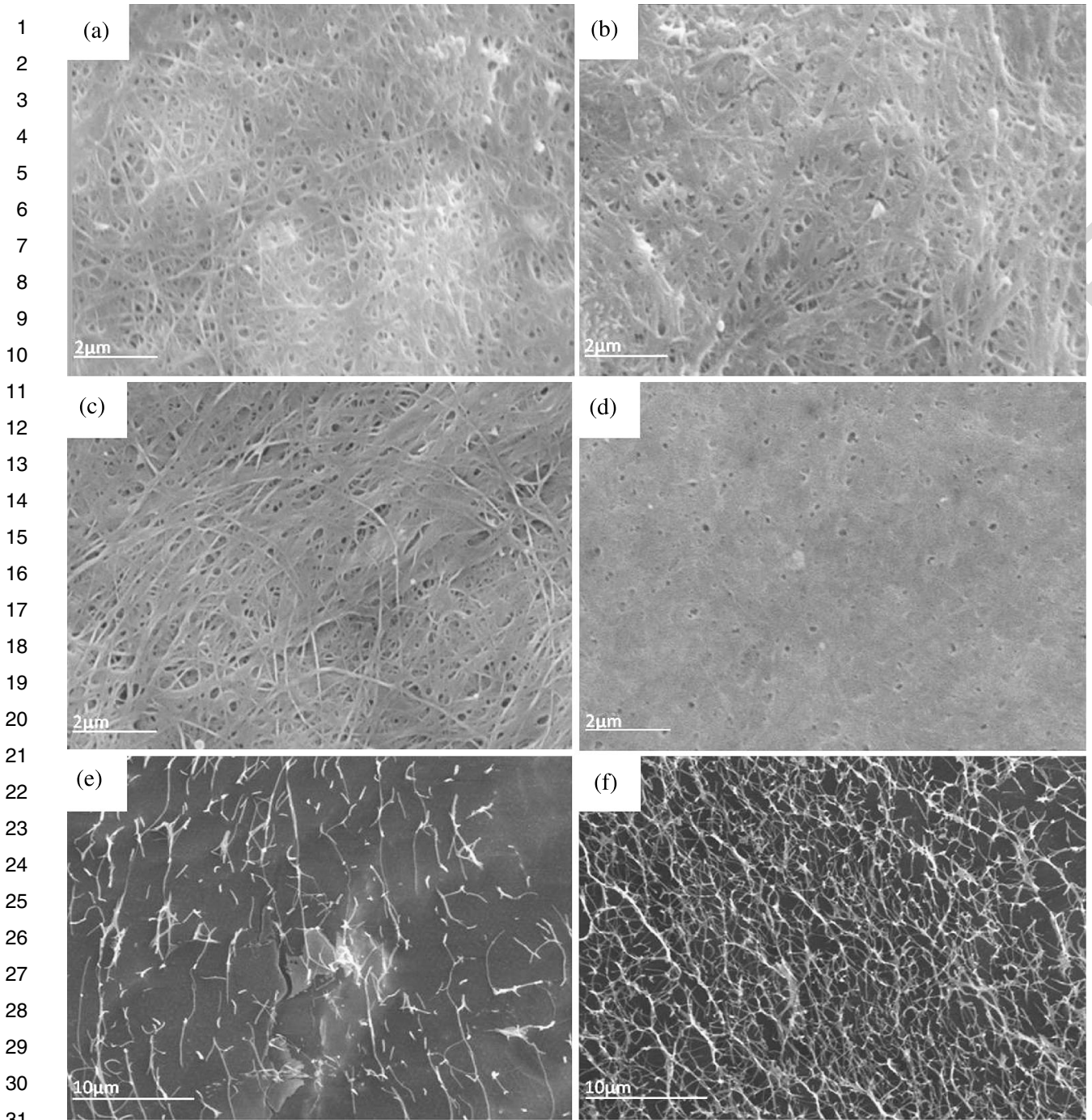

Figure 1. SEM micrographs of BC-1 and BC-2. (a) BC-2 porous side; (b) BC-2 compact side; (c) BC-1 porous side; (d) BC-1 compact side; and CryoSEM of BC-1 (e) porous side and (f) compact side.

focally obscured by incoming cells (Fig. 2). While with BC-1 cellular penetration was more intense through the porous side of the implants, in the case of the $\mathrm{BC}-2$ cells penetrated deeply through both sides of the implants.

$\mathrm{BC}$ did not elicit a foreign body reaction, and only a thin fibrous layer was formed. The membrane thickness showed differences between the two materials, ranging from 4 to $10 \mu \mathrm{m}$ for BC-2 and 5 to $60 \mu \mathrm{m}$ for BC-1. A mild, acute inflammation characterized by moderate oedema and increased numbers of neutrophils and less macrophages inside and around the implants was observed initially. From 


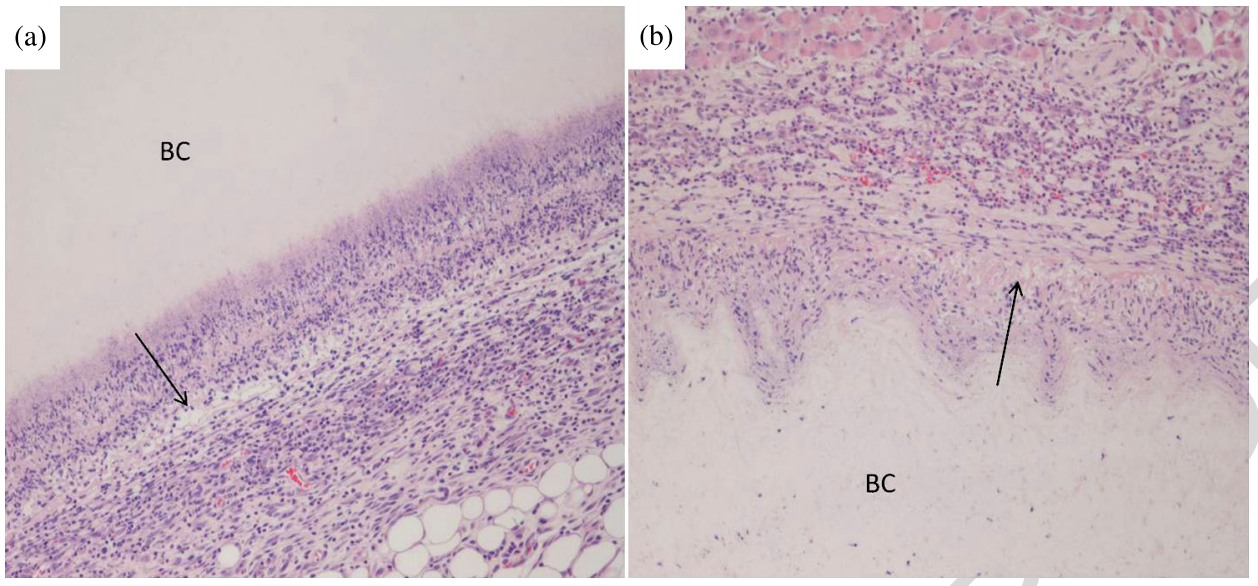

Figure 2. Histological images of BC-1, 1 week post-implantation, showing (a) BC-1 compact side and (b) BC-1 porous side; and the different pattern of cell infiltration $(\times 100)$. Arrow head shows the approximate surface between the implant and the connective tissue. This figure is published in colour in the online edition of this journal, which can be accessed via http://www.brill.nl/jbs

Table 1.

Qualitative scores of the biological reaction to the $\mathrm{BC}$ subcutaneous implant

\begin{tabular}{llll}
\hline Calcification & Inflammation & Blood vessels & \multicolumn{2}{l}{ Cell type } \\
\cline { 3 - 4 } & & M/N & Ms
\end{tabular}

$\mathrm{BC}-1$

1 week

1 month

3 months

5 months

7 months

12 months

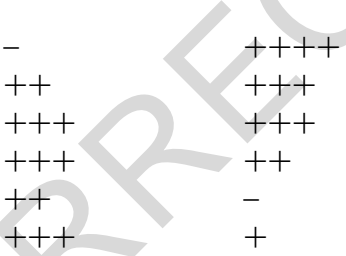

BC-2

1 week

1 month

3 months

5 months

7 months

12 months
$++++$

$++++$

$++$

$+++$

$+$

$-$

-
-
+
+
++
++

\section{$++++$}

\section{$++++$}

$++++$

$++++$

$++++$

$+++$

$+$

$+++$

$++++$

$++++$

$++++$ $+++$

$++$

$++$

$++$

$+$

$+$

$-$
++++ , all the implants present the condition; -, none of the implants present the condition; $\mathrm{M} / \mathrm{N}$, macrophages/neutrophils; Ms, mesenchymal cells.

4 weeks onwards, the cell response progressively evolved towards chronicity, with reduced inflammatory cells in and around the implants and a predominance of macrophages over neutrophils. Fibroblasts, endothelial cells and rare adipocytes (collectively referred to as mesenchymal cells in Table 1) invaded the implants. Af- 
ter 3 months, the macrophages, fibroblasts and endothelial cells were predominantly found in the implants. Table 1 summarizes the qualitative scores regarding different aspects of the biological reaction to the implants, with time, including calcification, inflammation, presence of blood vessels, and kind of cells observed. Newly formed blood vessels were observed next to the implants. In a few cases (mostly with BC-2 implants) blood vessels were also present inside the implants, although they did not reach the middle of the implant.

Calcification inside BC was observed in many cases (Table 1), as shown in Figs 3 and 4 . In the case of BC-2 calcification occurred, sporadically, 3 months postimplantation and earlier and consistently 1 month post-implantation in the case of BC-1. The calcification localization differed between the two types of implants: BC-1 implants calcified more heavily in the periphery, whereas the calcification of BC-2 was spread through the middle of the implant.

\subsection{BC Nanofibre Biocompatibility}

All animals implanted with cellulose nanofibres survived and showed a normal development within the time-course of the experiment. There were no significant changes in body weight between the implanted animals and control, nor did any animal show clinical signs of inflammation at the injection sites (data not shown). Histological examination showed a mild, chronic inflammatory process associated with injection sites on nanofibre-exposed mice. At 2 and 4 months post-implantation, nanofibres were present in subcutaneous foamy macrophages aggregates (Fig. 5a and 5c) as an abundant, lightly basophylic, intracytoplasmic, amorphous material (Fig. 5b and 5d). In some instances, nanofibres were still present as extracellular deposits surrounded by numerous foamy macrophages engaged in phagocytosis. Small, multifocal, peripheral, lymphoid aggregates and occasional mast cells were also present. Histological analysis of internal organs (small intestine, liver, spleen) showed no differences between implanted and control animals.

To assess the effect of BC nanofibres in leukocyte haemopoiesis, the proportion of different leukocyte cell populations was analyzed by flow cytometry in the thymus and bone marrow. As shown in Table 2, no significant alterations in the proportions of thymic double-positive $\left(\mathrm{CD} 4^{+} \mathrm{CD} 8^{+}\right)$, or single positive $\left(\mathrm{CD} 4^{+}\right.$and $\mathrm{CD}^{+}$) cells were observed in the implanted animals, comparatively to controls, at the time-points analyzed. As also shown in Table 2, no significant effect of nanofibre implants was observed in B-cell lineage populations in the bone marrow, as assessed in both pre/pro B $\left(\mathrm{B}_{2} 20^{+} \mathrm{IgM}^{-}\right)$, and B immature/mature $\left(\mathrm{B} 220^{+} / \mathrm{IgM}^{+}\right)$ cells. Furthermore, the proportion of bone marrow myeloid/granulocytes cell population $\left(\mathrm{CD} 11 \mathrm{~b}^{+} / \mathrm{GR} 1^{+}\right)$was also not different from that of controls 2 and 4 months after nanofibre implant. Altogether, these results indicate that no significant effect in leukocyte haematopoiesis was caused by the implanted BC nanofibres (NFs). 

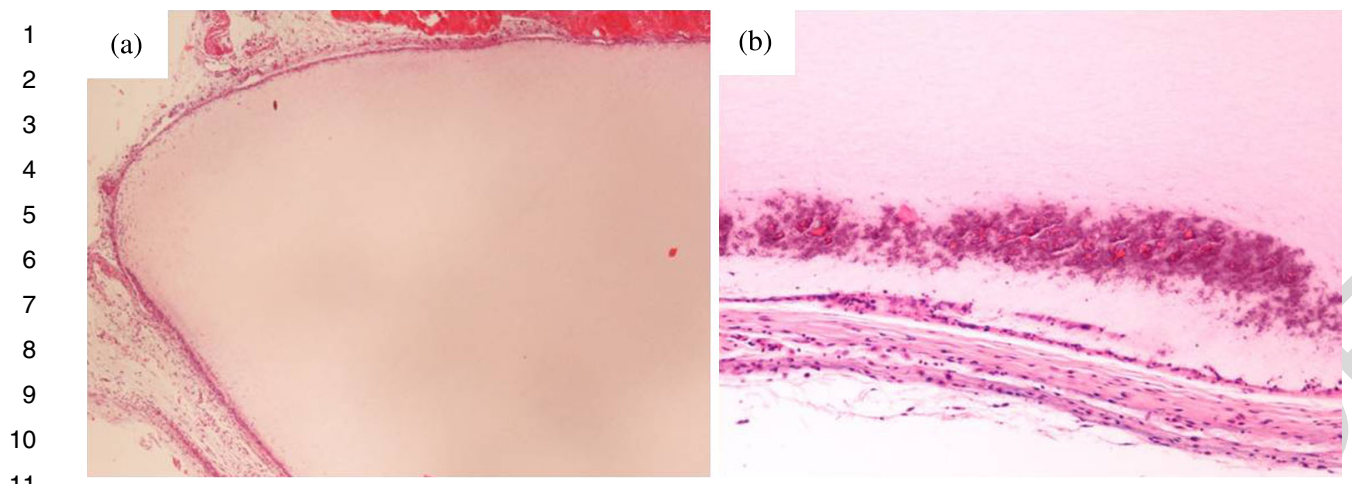

(c)

(d)
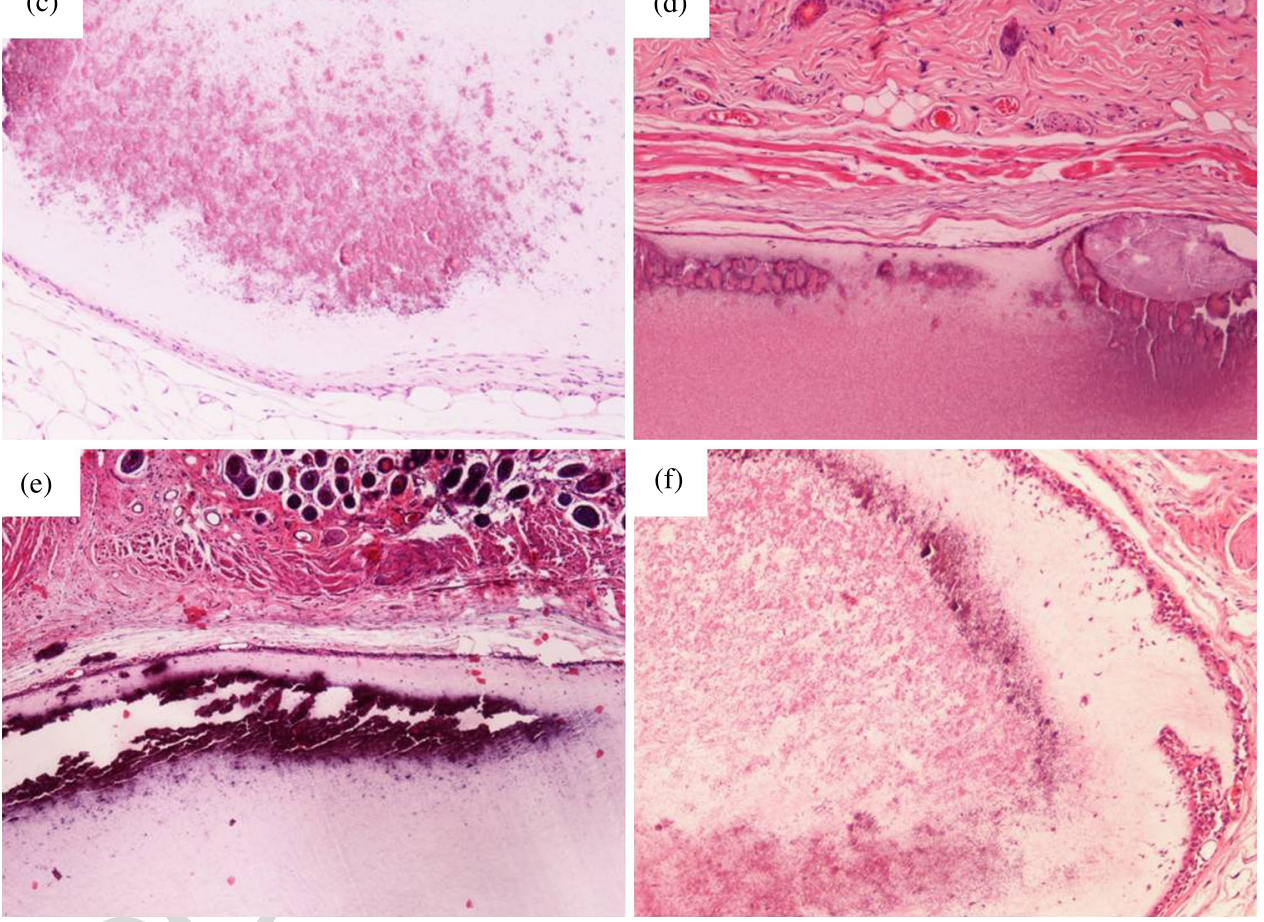

Figure 3. BC-1 implants at (a) 1 week, (b) 1 month, (c) 3 months, (d) 5 months, (e) 7 months and (f) 12 months post-implantation $(\times 100)$. This figure is published in colour in the online edition of this journal, which can be accessed via http://www.brill.nl/jbs

\section{Discussion}

Biocompatibility is one of the main requirements of any biomedical material and can be defined as the ability to remain in contact with living tissue without causing any toxic or allergic side-effects [1]. BC is generally considered a biocompatible material, although, to our knowledge, only two papers reported the study of the fate of sub-cutaneous BC implants in vivo; in these cases, the studies were conducted 
(a)
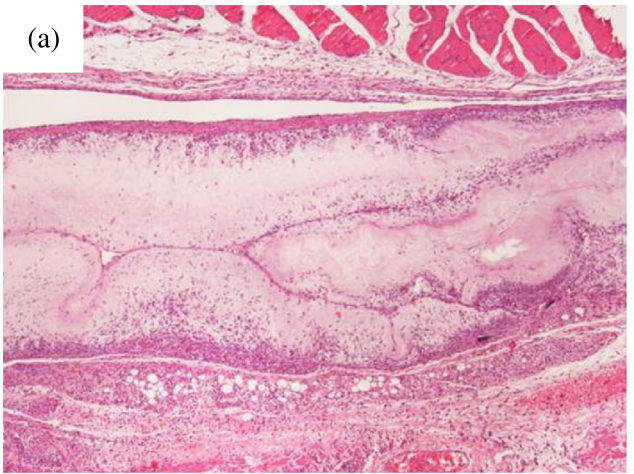

(c)
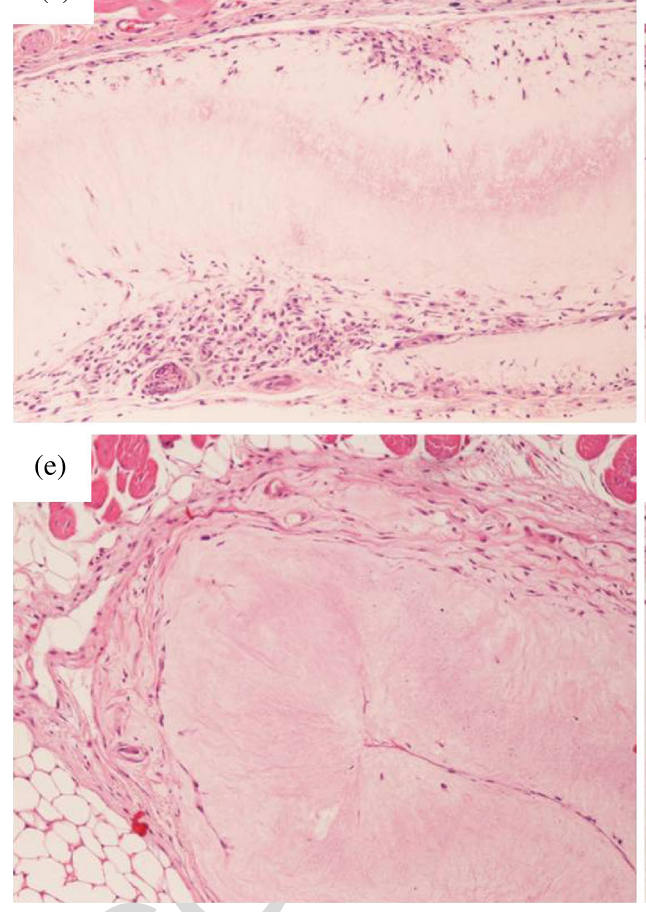

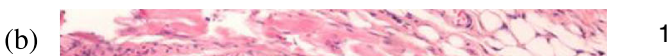
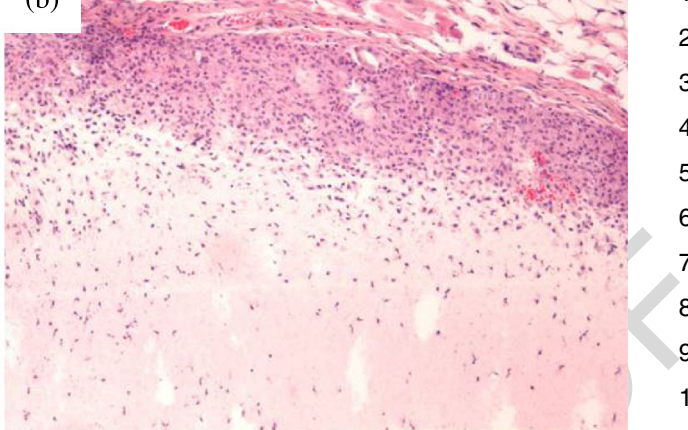

(d)
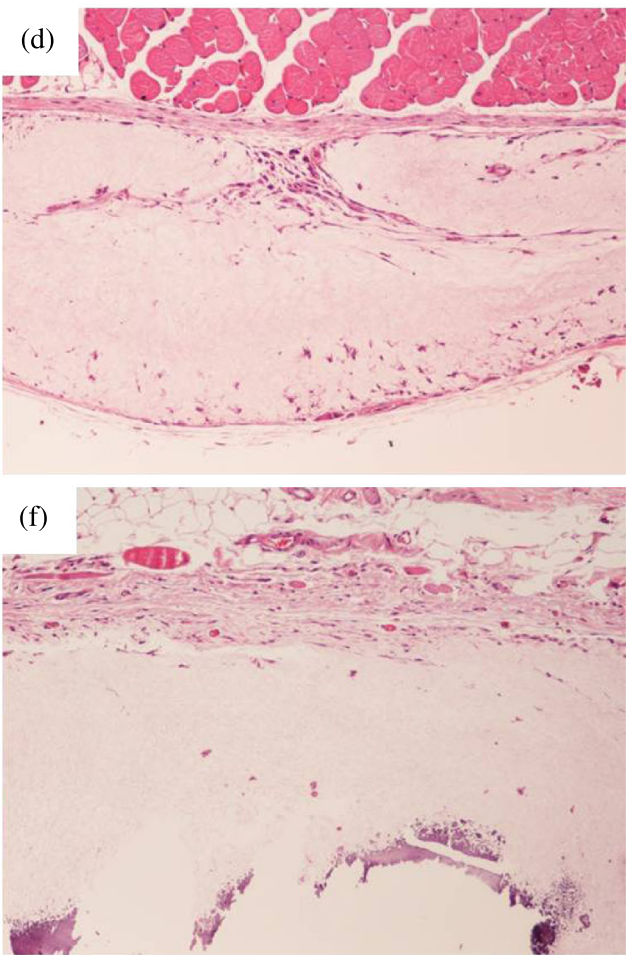

Figure 4. BC-2 implants at (a) 1 week, (b) 1 month, (c) 3 months, (d) 5 months, (e) 7 months and (f) 12 months post-implantation $(\times 100)$. This figure is published in colour in the online edition of this journal, which can be accessed via http://www.brill.nl/jbs

for relatively short periods (up to 12 weeks). In this work, the fate of implanted BC along much longer periods of time (up to 1 year), possible differences associated to the structure (namely porosity) of the material and possible toxicity effects related to $\mathrm{BC}$ nanofibres were analyzed.

As expected, the BC implants in the present experiment did not elicit a foreign body reaction. Only a thin capsule was formed over time, its thickness depending on the kind of implant (BC-1 implants elicited a stronger encapsulation than 

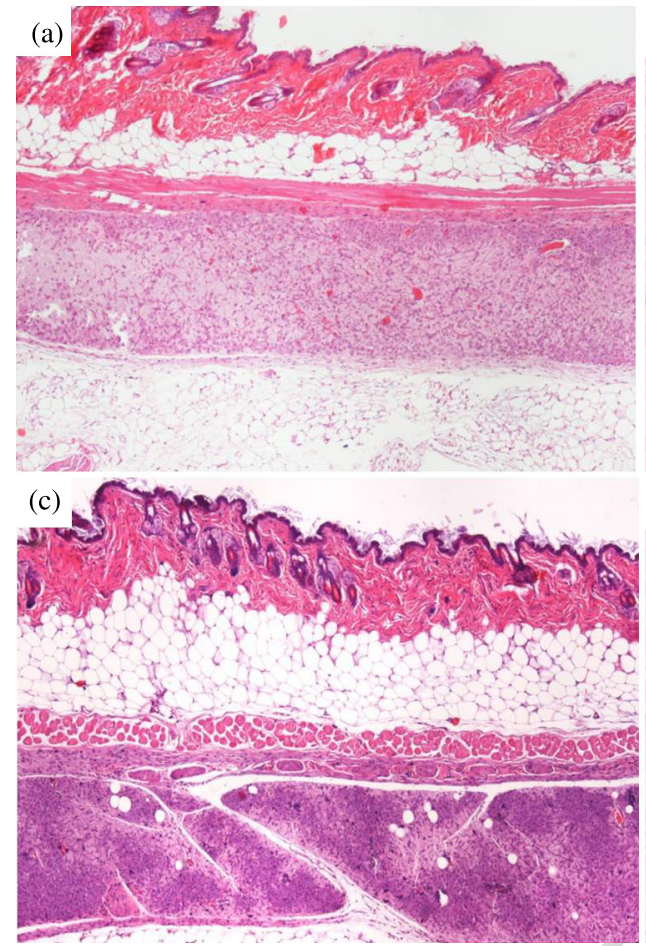

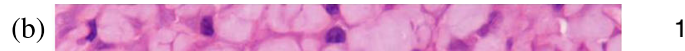

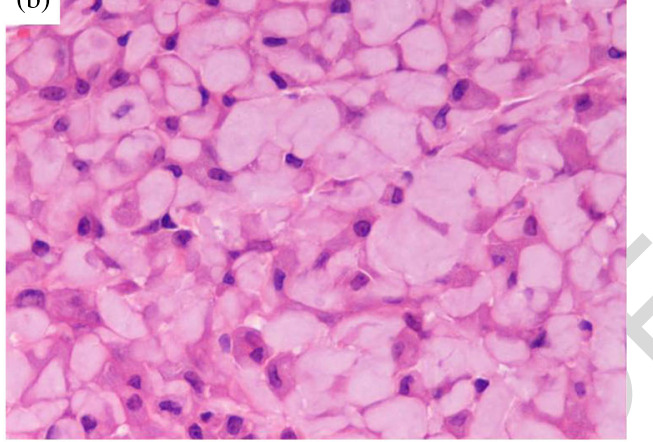

(d)

Figure 5. Nanofibres implants at (a) 2 months $(\times 40)$, (b) 2 months $(\times 400)$, (c) 4 months $(\times 40)$ and (d) 4 months $(\times 400)$, post implantation. (a, c) Nanofibre aggregates in the subcutaneous tissue; (b, d) macrophages with intracellular BC material. This figure is published in colour in the online edition of this journal, which can be accessed via http://www.brill.nl/jbs

BC-2). The inflammatory reaction caused by the implants was mild and did not cause any complications. In the first weeks, the cells colonizing the implants were mostly neutrophils and macrophages. However, over time, macrophages became predominant over neutrophils, and fibroblasts and endothelial cells were the main cell types within the implants, although blood vessels were restricted to the implant's periphery. Integration with the host tissue was multifocally present, in areas where incoming cells obscured.

These results are in agreement with Helenius et al. [8] who implanted BC subcutaneously in mice, for a period of up to 12 weeks. No signs of chronic inflammatory reaction or capsule formation were verified in that case, and the formation of new blood vessels around and inside the implants was observed [8]. In another work, Mendes et al. [23] subcutaneously implanted BC was shown to be non-resorbable and capable of inducing a mild inflammatory response. The authors observed no inflammatory infiltrate at 60 and 90 days post-surgery. The angiogenesis was markedly reduced and the connective tissue surrounding the membrane was mature [23]. 
R. A. N. Pértile et al. / Journal of Biomaterials Science 0 (2011) 1-16

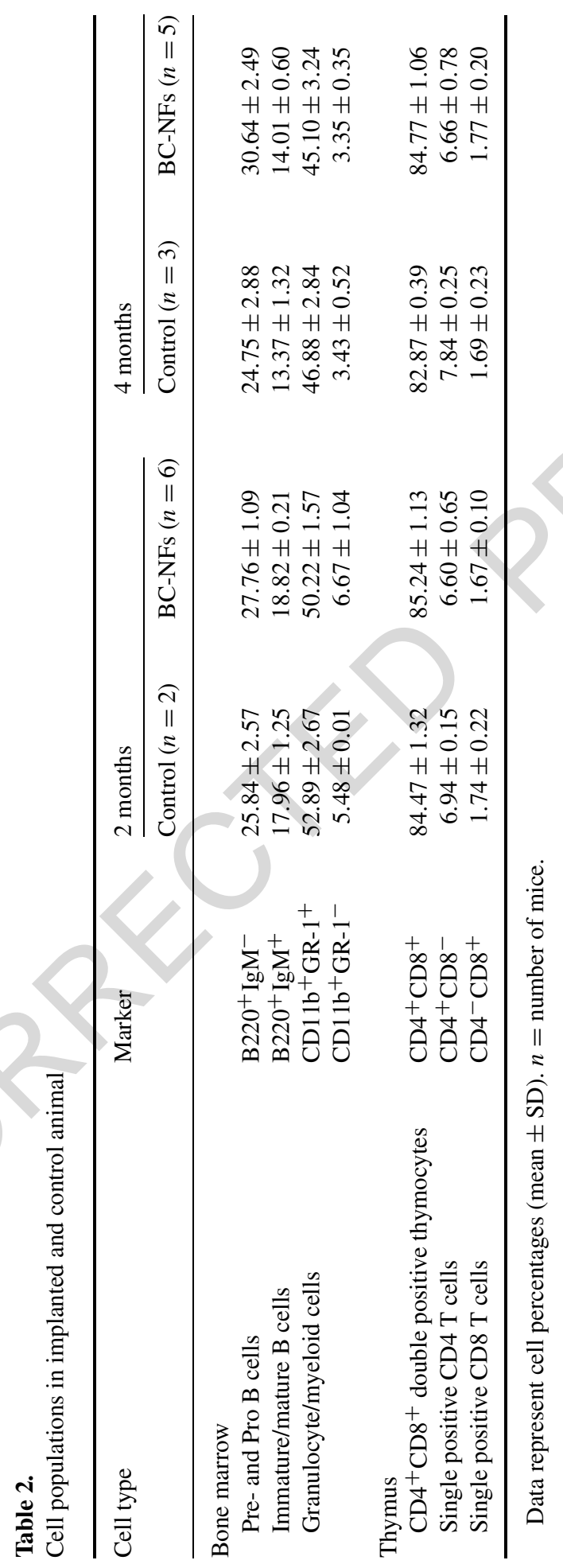

1 2 3 4 5 6 7 8 9 10 
In this work, the structural differences between BC produced by the different $G . \quad 1$ xylinus strains determined the cell behaviour in the implants. In the case of BC-2 2 membranes, cells were able to migrate into the inner membranes and colonize their full extent. In the case of $\mathrm{BC}-1$, cell migration was conditioned by the tight pores, and by the compact and soft sides, cells being unable to reach the inner portion of the implants. As described by Helenius et al., our results indicate that the magnitude of cell in-growth seems to be dependent on the porosity of BC, cell migration declining where the material is denser [8].

In this study, in contrast to earlier reports referred, BC calcification was, for the first time, observed. This type of calcification may be due to the occurrence of cell death inside the $\mathrm{BC}$ structure. Cell death results in an acid environment in the implant, conducive for the mobilization and concentration of calcium. The tentative explanations of biomaterials calcification assign the main cause to dead cells. According to this hypothesis, the accumulation of calcium deposits originates from the cells or tissues that have degenerated or become necrotic [25, 26]. However, some authors showed that, even without direct contact with cells, calcification of biomaterials occurs through the formation of a protein-calcium complex layer on the surface of biomaterials, this being the key event in biomaterial calcification [27, 28]. Furthermore, Rosanova et al. [28] suggested that the formation of calcium deposits occurs by the adsorbed protein molecules, which bind $\mathrm{Ca}^{2+}$ ions from surrounding media; alternatively, Ca-protein complexes forms at the biomaterial/blood interface and adsorbs onto the surface.

This work provides clues regarding the factors influencing $\mathrm{BC}$ calcification. The porosity and time of implantation are factors that seem to influence calcification, considering that the two BCs used presented different calcification patterns (peripheral versus diffuse). Calcification only occurred in the implants where cells were present, preferentially in the interior of the implant, and at different times according to the type of cellulose. The findings suggest that the differences in membrane size and the longer observation period compared with previous studies [8, 23, 29] may have led to different observations in our study.

\subsection{Nanofibres}

Nanofibre matrices are well suited to tissue engineering: (1) as scaffold that can be fabricated and shaped to fill anatomical defects; (2) its architecture can be designed to provide the mechanical properties necessary to support cell growth, proliferation, differentiation and motility; (3) and it can be engineered to provide growth factors, drugs, therapeutics and genes to stimulate tissue regeneration. An inherent property of nanofibre scaffolds is that they resemble some features of the extracellular matrices, also a network of nanometer-sized biomacromolecules [30, 31]. Furthermore, its nanoscale dimension can provide tensile strength and elasticity for the tissues [4]. Although BC is not expected to be resorbable, some authors show evidence that amorphous BC may undergo degradation in vivo. Thus, the possibility that nanofibres may be released from implanted made materials cannot be 
ruled out, hence, the need to study the toxicity of BC nanofibres. Indeed, since the 1 nanomaterials have unusual properties, not found in the bulk material, such as high surface reactivity and ability to cross cell membranes, concerns about their safety and toxicology emerged [6]. The impact of nanostructural features in the interaction of a material with cells and tissues is dependent on the size, chemical composition, surface structure, solubility, shape and on the supramolecular structural organization $[5,6]$. In this context, the toxicity of nanoscale substances has been studied since it is known that carbon nanotubes and asbestos are nanoscale materials with carcinogenic potential [32-34].

Moreira and co-workers presented the first evaluation of the potential genotoxicity of BC nanofibres and showed that BC NFs did not present genotoxicity in vitro [6]. However, an in vivo study is still missing and it is well known that with the in vitro systems there is no possibility to evaluate secondary inflammatory effects [6]. Some studies with cellulose fibres described the biological effects of this type of material in animal studies. Cellulose fibres tested in vivo showed no adverse health effects when chronically ingested, but when present in the intraperitoneal region can cause mesothelioma in rats, and when inhaled, have the potential to accumulate and induce pathological changes in the lung [35-37]. In this work, most injected nanofibres remained in macrophage aggregates in the subcutaneous tissue and did not cause any visible abnormalities, neither in the host adjacent tissue, nor in the abdominal organs. These results are in agreement to studies conducted with carbon nanotubes and carbon nanotubes/polycarbosilane composites, which were implanted in the subcutaneous tissue of rats and showed no acute inflammatory response, such as necrosis. In addition, the carbon nanofibres were internalized by the macrophages and foreign body giant cells, which were found in the implants local $[38,39]$.

Systematic analyses of nanomaterials biocompatibility are essential to the use of these structures in tissue-engineering applications. The in vivo systemic effects of nanomaterials were studied by some authors, for instance, activated carbon fibres and asbestos implanted subcutaneously in mice were analyzed by Koyama and co-workers, who found that asbestos-implanted tissue showed a severe inflammatory reaction and formation of abscess-like mass in the implanted tissue along with low values of peripheral blood $\mathrm{CD}^{+}{ }^{+}$and $\mathrm{CD} 8^{+} \mathrm{T}$ cells [40]. Koyama also showed the relative low toxicity of different types of carbon nanotubes, subcutaneously implanted in mice. The carbon nanotubes gave rise to several characteristic time-dependent changes in $\mathrm{CD}^{+}$and $\mathrm{CD}^{+} \mathrm{T}$-cell values [3]. Furthermore, it was shown that the inhalation of asbestos has adverse effects in leukopoiesis in mice, leading to a depression of the number of bone marrow pluripotent stem cells and marrow granulocyte macrophage progenitors [41]. In our work, the absence of BC nanofibres toxicity in vivo was further evidenced by the absence of observed disease features in mice. Flow cytometry analyses did not show any significant effect in leukocyte haematopoiesis caused by the implanted BC nanofibres. No significant alterations in the proportions of thymic double positive $\left(\mathrm{CD} 4^{+} \mathrm{CD} 8^{+}\right)$, single posi- 
tive $\left(\mathrm{CD} 4^{+}\right.$and $\left.\mathrm{CD} 8^{+}\right)$cells, B-cell lineage populations and myeloid/granulocytes cell population $\left(\mathrm{CD} 11 \mathrm{~b}^{+} / \mathrm{GR} 1^{+}\right)$were observed in the bone marrow, in the implanted animals comparatively to controls. Therefore, these results indicate that BC nanofibres did not cause a significant inflammatory response and can be considered an innocuous material in vivo, suitable for tissue-engineering applications.

\section{Conclusions}

$\mathrm{BC}$ is considered a great material to implants with good biocompatibility characteristics. However, our work points to the necessity to further investigation to verify the tendency of $\mathrm{BC}$ to calcify in long-term in vivo circumstances. Porosity is likely to be the main limitation for a widespread colonization of the material, allowing for proper tissue integration and the production of neo-tissues with excellent mechanical properties. The calcification detected in this work seems to be mainly dependent on the material's porosity and on the exposure period. Although calcification is an undesirable fate for such a biomaterial, it should be remarked that such events may be dependent on the tissue where the biomaterial is to be placed. On the other hand, a proper porosity allowing angiogenesis and adequate nutrients supply to the cells may avoid the calcification processes. BC nanofibres seem to be an innocuous material in mice subcutaneous tissue, and have been proven to be an eligible material to production of tissue-engineering grafts.

\section{Acknowledgements}

R. A. N. P. gratefully acknowledges support by the Programme $\mathrm{Al} \beta$ an, the European Union Programme of High Level Scholarships for Latin America (Scholarship No. E07D401931BR). S. M. is recipient of a SFRH/BPD/64726/2009 fellowship from Fundação para a Ciência e a Tecnologia (FCT, Portugal). R. M. G. da C. (SFRH/BD/37565/2007) and A. C. (SFRH/BD/31354/2006) are recipients of a PhD fellowship from Fundação para a Ciência e a Tecnologia (FCT, Portugal). Funding by FCT through the program PTDC is greatly acknowledged.

\section{References}

1. W. K. Czaja, D. J. Young, M. Kawecki and R. M. Brown, Biomacromolecules 8, 1 (2007).

2. B. S. Kim and D. J. Mooney, Trends Biotechnol. 16, 224 (1998).

3. S. Koyama, M. Endo, Y. A. Kim, T. Hayashi, T. Yanagisawa, K. Osaka, H. Koyama, H. Haniu and N. Kuroiwa, Carbon 44, 1079 (2006).

4. Z. W. Ma, M. Kotaki, R. Inai and S. Ramakrishna, Tissue Eng. 11, 101 (2005).

5. C. A. Barnes, A. Elsaesser, J. Arkusz, A. Smok, J. Palus, A. Lesniak, A. Salvati, J. P. Hanrahan, W. H. de Jong, E. Dziubaltowska, M. Stepnik, K. Rydzynski, G. McKerr, I. Lynch, K. A. Dawson and C. V. Howard, Nano Lett. 8, 3069 (2008).

6. S. Moreira, N. B. Silva, J. Almeida-Lima, H. A. O. Rocha, S. R. B. Medeiros, C. Alves and F. M. Gama, Toxicol. Lett. 189, 235 (2009). 
7. F. A. Muller, L. Muller, I. Hofmann, P. Greil, M. M. Wenzel and R. Staudenmaier, Biomaterials 27, 3955 (2006).

8. G. Helenius, H. Backdahl, A. Bodin, U. Nannmark, P. Gatenholm and B. Risberg, J. Biomed. Mater. Res. A 76, 431 (2006).

9. J. G. Doheny, E. J. Jervis, M. M. Guarna, R. K. Humphries, R. A. J. Warren and D. G. Kilburn, 5 Biochem. J. 339, 429 (1999).

10. E. Entcheva, H. Bien, L. H. Yin, C. Y. Chung, M. Farrell and Y. Kostov, Biomaterials 25, 5753 (2004).

11. M. Martson, J. Viljanto, T. Hurme and P. Saukko, Eur. Surg. Res. 30, 426 (1998).

12. J. A. LaIuppa, T. A. McAdams, E. T. Papoutsakis and W. M. Miller, J. Biomed. Mater. Res. 36, 347 (1997).

13. H. Pulkkinen, V. Tiitu, E. Lammentausta, E. R. Hamalainen, I. Kiviranta and M. J. Lammi, Biomed. Mater. Eng. 16, S29 (2006).

14. R. Jonas and L. F. Farah, Polym. Degrad. Stabil. 59, 101 (1998).

15. D. Klemm, D. Schumann, U. Udhardt and S. Marsch, Prog. Polym. Sci. 26, 1561 (2001).

16. D. Klemm, B. Heublein, H. P. Fink and A. Bohn, Angew. Chem. Int. Edn 44, 3358 (2005).

17. R. M. Brown and I. M. Saxena, Plant Physiol. Biochem. 38, 57 (2000).

18. A. N. Nakagaito, S. Iwamoto and H. Yano, Appl. Phys. A: Mater. Sci. Process. 80, 93 (2005).

19. E. J. Vandamme, S. De Baets, A. Vanbaelen, K. Joris and P. De Wulf, Polym. Degrad. Stabil. 59, 93 (1998).

20. J. D. Fontana, A. M. Desouza, C. K. Fontana, I. L. Torriani, J. C. Moreschi, B. J. Gallotti, S. J. Desouza, G. P. Narcisco, J. A. Bichara and L. F. X. Farah, Appl. Biochem. Biotechnol. 24-25, 253 (1990).

21. H. Backdahl, G. Helenius, A. Bodin, U. Nannmark, B. R. Johansson, B. Risberg and P. Gatenholm, Biomaterials 27, 2141 (2006).

22. A. Linde, P. Alberius, C. Dahlin, K. Bjurstam and Y. Sundin, J. Periodontol. 64, 1116 (1993).

23. P. N. Mendes, S. C. Rahal, O. C. M. Pereira-Junior, V. E. Fabris, S. L. R. Lenharo, J. F. de LimaNeto and F. D. Landim-Alvarenga, Acta Vet. Scand. 51, 12 (2009).

24. S. Hestrin and M. Schramm, Biochem. J. 58, 345 (1954).

25. K. M. Kim, Scanning Microsc. 9, 1137 (1995).

26. Zainuddin, T. V. Chirila, D. J. T. Hill and A. K. Whittaker, J. Mol. Struct. 739, 199 (2005).

27. S. L. Vasin, I. B. Rosanova and V. I. Sevastianov, J. Biomed. Mater. Res. 39, 491 (1998).

28. I. B. Rosanova, B. P. Mischenko, V. V. Zaitsev, S. L. Vasin and V. I. Sevastianov, J. Biomed. Mater. Res. 25, 277 (1991).

29. J. Wippermann, D. Schumann, D. Klemm, H. Kosmehl, S. Salehi-Gelani and T. Wahlers, Eur. J. Vasc. Endovasc. Surg. 37, 592 (2009).

30. S. Ramakrishna, K. Fujihara, W. E. Teo, T. Yong, Z. W. Ma and R. Ramaseshan, Mater. Today 9 , 40 (2006).

31. Q. P. Pham, U. Sharma and A. G. Mikos, Tissue Eng. 12, 1197 (2006).

32. G. Speit, Inhalation Toxicol. 14, 79 (2002).

33. K. Donaldson, R. Aitken, L. Tran, V. Stone, R. Duffin, G. Forrest and A. Alexander, Toxicol. Sci. 92, 5 (2006).

34. C. A. Poland, R. Duffin, I. Kinloch, A. Maynard, W. A. H. Wallace, A. Seaton, V. Stone, S. Brown, W. MacNee and K. Donaldson, Nature Nanotechnol. 3, 423 (2008).

35. R. L. Anderson, J. W. Owens and C. W. Timms, Cancer Lett. 63, 83 (1992).

36. Z. Adamis, E. Tatrai, K. Honma, J. Karpati and G. Ungvary, Ann. Occup. Hyg. 41, 515 (1997).

37. R. T. Cullen, B. G. Miller, S. Clark and J. M. G. Davis, Inhalation Toxicol. 14, 685 (2002). 
38. A. Yokoyama, Y. Sato, Y. Nodasaka, S. Yamamoto, T. Kawasaki, M. Shindoh, T. Kohgo, 1 T. Akasaka, M. Uo, F. Watari and K. Tohji, Nano Lett. 5, 157 (2005).

39. W. Wang, F. Watari, M. Omori, S. Liao, Y. H. Zhu, A. Yokoyama, M. Uo, H. Kimura and 3

A. Ohkubo, J. Biomed. Mater. Res. B 82, 223 (2007).

40. S. Koyama, S. Tanaka, Y. Yamaguchi, H. Haniu, G. Konishi and H. Koyama, Mol. Cryst. Liq. 5 Cryst. 388, 581 (2002). 6

41. G. A. Boorman, J. H. Dean, M. I. Luster, B. Adkins, A. Brody and H. L. Hong, Toxicol. Appl. 7 Pharm. 72, 148 (1984). 